Article

\title{
Comprehensive Instrumental Odor Analysis Using SIFT-MS: A Case Study
}

\author{
Vaughan S. Langford ${ }^{1}$, Murray J. McEwan ${ }^{1,2, *}$, Mary Askey ${ }^{3}$, Helena A. Barnes ${ }^{1}$ and \\ James G. Olerenshaw ${ }^{1}$ \\ 1 Syft Technologies Ltd., 3 Craft Pl, Christchurch 8242, New Zealand; vaughan.langford@syft.com (V.S.L.); \\ helena.barnes@syft.com (H.A.B.); James.olerenshaw@syft.com (J.G.O.) \\ 2 Department of Chemistry, University of Canterbury, PB 4800, Christchurch 8140, New Zealand \\ 3 Gelita NZ, 135 Connal St, Woolston, Christchurch 8023, New Zealand; Mary.Askey@gelita.com \\ * Correspondence: murray.mcewan@canterbury.ac.nz; Tel.: +64-27-461-0336
}

Received: 12 February 2018; Accepted: 22 March 2018; Published: 23 March 2018

\begin{abstract}
Instrumental analysis of odor is challenging due to the chemical diversity of many important odorants, the high sensitivity required to achieve human odor thresholds, and the dynamic nature of the odor itself. Conventional sensor-based and chromatographic technologies are poorly suited to the task. In this paper, we apply a novel direct mass spectrometric technique-selected ion flow tube mass spectrometry (SIFT-MS) - to the chemical analysis of odor. The SIFT-MS technique provides comprehensive real-time odor analysis through detection and quantitation of all odorants, including aldehydes, amines, organosulfur compounds, and volatile fatty acids. In the case study described, SIFT-MS is utilized to monitor specific odor compounds at a gelatin factory in Christchurch, New Zealand. Odor composition from various steps in the gelatin manufacturing process was determined using SIFT-MS in scan mode. Over a period of several years, the gelatin manufacturer made improvements to their plant to reduce fugitive odors, and sources were re-analyzed. In this investigation, SIFT-MS analysis was utilized to evaluate the effectiveness of an odor neutralization technology based on UV photolysis at the plant.
\end{abstract}

Keywords: environmental odor; SIFT-MS; gelatin; manufacture; odor reduction

\section{Introduction}

Odors can have a significant influence on human behavior and on the quality of life. Many industries that people work in generate odors and some industries, particularly those that utilize animals and animal waste products, may generate volatile compounds-such as organosulfur compounds, volatile fatty acids, and amines - to which the human nose is particularly sensitive. To establish acceptable standards for odor emissions, the human nasal response alone cannot be relied on because it is subjective and variable [1-5]. Nasal odor thresholds are not always reliable and may be ignored on occasions as they are too low for easy detection, or from prior conditioning of the nose to the levels being experienced. However, it also should be recognized that some odors may be detected by the nose that are below instrument thresholds [3].

Instrumental detection of odors, although not subject to the variability of the human nose, is challenging due to the chemical diversity of the odorants, the high sensitivity that is required for identification and monitoring and the dynamic change of the odors with experimental and atmospheric conditions. There is an extensive literature available on odor monitoring using a variety of different techniques. These range from instrument-based techniques like gas chromatography mass spectrometry (GC/MS) where the odor molecules are separated in a chromatographic column before detection [6] to olfactory techniques which allow human evaluators $[7,8]$ to sensor-based technologies 
embracing a wide range of different detectors [9-11]. Conventional sensor-based and chromatographic techniques are not well suited to the task of monitoring odors due to the rapidly changing and variable nature of the emissions [12-16]. New direct technologies without chromatography are now being applied to odor monitoring and one of these techniques, selected ion flow tube mass spectrometry (SIFT-MS) [17-20] is presented here. In this paper, one application of instrumental monitoring of odors in the vicinity of a gelatin factory is discussed.

Gelatin is a mixture of peptides and proteins produced by partial hydrolysis of collagen that is extracted from the skin, bones, and connective tissue of animals such as cattle, chicken, pigs, and fish [21-23]. The process of conversion of animal byproducts into gelatin can be accompanied by odor production. In this case study of odor profiling, we show results obtained from analysis of the air around the Gelita gelatin factory located in Christchurch, New Zealand. This long-established factory pre-dates most of the residential and commercial property that surrounds it. Depending on climate conditions, there has been a history of odor production from the Gelita plant at times and the factory has been the subject of complaints from neighbors.

In 2017, Gelita evaluated a Neutralox ${ }^{\circledR}$ photoionization plant $[24,25]$ which utilizes UV light to photo-convert odorant molecules - such as sulfides, mercaptans, and ammonia-into non-odorous species. In this study, we monitor the concentrations of odorant molecules before and after the installation of the deodorization plant. SIFT-MS is a direct monitoring technique [17-20] and is utilized here as the means of monitoring odor within the factory vicinity.

\section{Materials and Methods}

Each day, conditioned cattle hide is transferred from the alkaline lime pits via the loading screws shed to the tumblers for acidulation. The hide has been conditioned with lime and caustic soda and is highly alkaline ( $\mathrm{pH} 12)$. Prominent odors generated in this process include ammonia, hydrogen sulfide, and trimethylamine.

A SIFT-MS instrument (Figure 1; Syft Technologies Syft Voice200, Christchurch, New Zealand; www.syft.com) was used to analyze the odor compounds generated at the different sites within the Gelita plant.

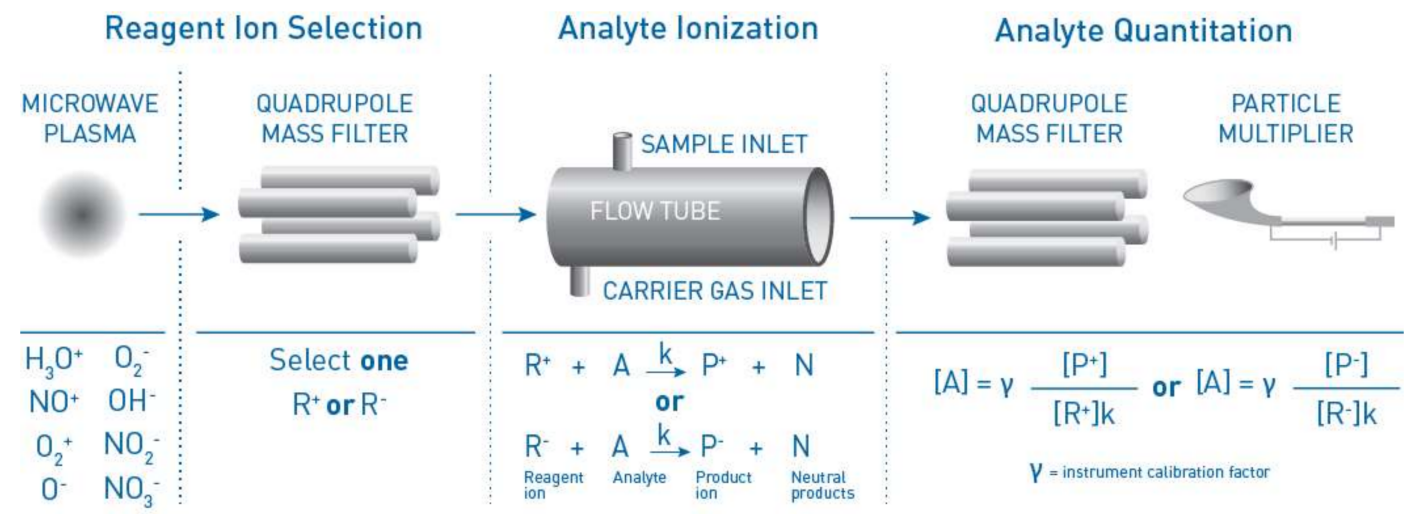

Figure 1. Schematic representation of the selected ion flow tube mass spectrometry (SIFT-MS) technique (reproduced with permission of Syft Technologies).

SIFT-MS technology [17-20] utilizes known ion-molecule reactions of mass-selected reagent ions to quantify the concentrations of odorant molecules. The known rate coefficients and product ion ratios of the reagent ion-analyte reaction enable the odorant concentration to be determined [17]. Although eight reagent ions are available from a microwave discharge of moist air in current generation commercial instruments (Figure 1) [20], for the present study, only the positively charged reagent ions $\mathrm{H}_{3} \mathrm{O}^{+}, \mathrm{NO}^{+}$, and $\mathrm{O}_{2}{ }^{+}$were utilized. Simultaneous analysis of chemically diverse volatile compounds is provided by SIFT-MS as no time-consuming chromatography is required. With these reagent 
ions, chemically diverse odorant compounds such as reduced sulfur compounds, ammonia, amides, aldehydes (including formaldehyde), and volatile fatty acids including formic acid and acetic acid may be analyzed together in a simple single analysis [26-31].

In SIFT-MS, it is the reagent ion chemistry that enables the analyte concentration to be measured. In this investigation, three positively charged reagent ions were used: $\mathrm{H}_{3} \mathrm{O}^{+}, \mathrm{NO}^{+}$, and $\mathrm{O}_{2}{ }^{+}$. Smith and Spanel [17] have shown that the analyte concentrations are found simply by monitoring the ratio of product ion count to reagent ion count-see caption under Analyte Quantitation in Figure 1. To achieve accurate ratios of product ion to reagent ion count, the mass spectrometer/multiplier system at the downstream end of the flow tube needs to be calibrated and this calibration is achieved using a known mixture of eight reference gas analytes in nitrogen. In addition, standard samples were also available for some odorant molecules as a check on the analysis: e.g., a certified gas sample of $\mathrm{H}_{2} \mathrm{~S}$ at $25 \mathrm{ppmv}$ was available.

In the measurements described in this work, the SIFT-MS instrument was validated each day by monitoring a known mixture of eight analytes in $\mathrm{N}_{2}$ at the $2.0 \mathrm{ppmv}$ level. The rate coefficients for the $\mathrm{H}_{3} \mathrm{O}^{+}, \mathrm{NO}^{+}$, and $\mathrm{O}_{2}{ }^{+}$reagent ion-analyte reactions with all the odorant molecules are known. In the current study, the rate coefficients for ammonia, dimethylamine, and trimethylamine were from ref [29]: for hydrogen sulfide and methanethiol from [28]; for ethyl mercaptan from [27]; for formaldehyde from [26,30] and for acetic acid from [31]. Comparative studies of SIFT-MS with permeation tubes containing a wide range of analytes after reference gas calibration has shown agreement to the stated concentration within $\pm 5 \%$. Another benefit of SIFT-MS is the linearity with concentration. In another study, a series of selected volatiles at ppmv concentrations prepared in 1L Tedlar bags were sequentially diluted with zero grade air to generate a series of measurements at different concentrations between $5 \mathrm{ppbv}$ and 1 ppmv. The linearity of the concentrations in all cases as expressed by $\mathrm{R}^{2}$, the coefficient of determination, over three orders of magnitude examined was $R^{2} \geq 0.997$ [32]. A linear response over five orders of magnitude dilution is typical [33].

For the present work, samples were collected in $1 \mathrm{~L}$ Tedlar sample bags (SKC Inc., Eighty-Four, PA, USA) from the Gelita site and analyzed by the Voice200 SIFT-MS instrument (Syft Technologies Ltd, Christchurch, New Zealand). Each bag was flushed three times with zero air and analyzed as a blank prior to emptying and sample collection at the Gelita site. Bags were analyzed within two hours of collection to minimize losses of odorants. Data presented here represent blank-corrected concentrations based on subtraction of the blank values for the specific sampling bag, due to the variable low-ppb background in the bags $[34,35]$ and are the average of three replicate measurements.

For accurate monitoring of the odorant mixtures, the selected ion monitoring mode was used. During these analyses, the downstream mass spectrometer is tuned to the mass of the ion product of the odorant molecule generated by the reagent ion and the product ion counts are averaged over several seconds. The time taken for analysis of eight odorant molecules in a mixture is typically around 60 seconds. Isobaric interferences in mixtures of multiple analytes if they occur, can be resolved in most cases by interchanging the reagent ions. In most SIM scans the reproducibility is $\pm 15 \%$. During the SIM scan, dwell times for individual masses were typically $100 \mathrm{~ms}$ and count rates ranged from 100,000 cps for $\mathrm{NH}_{3}$ using the $\mathrm{O}_{2}{ }^{+}$reagent ion and 12,000 cps for trimethylamine using both $\mathrm{NO}^{+}$and $\mathrm{O}_{2}{ }^{+}$reagent ions choosing $\mathrm{NH}_{3}$ and $\mathrm{C}_{3} \mathrm{H}_{9} \mathrm{~N}$ as examples before passage through the photoionization deodorizer. The limit of detection for the odorant molecules was $\leq 5 \mathrm{ppbv}$.

The following reagent ions were used in the odorant molecule analysis: ammonia $\left(\mathrm{O}_{2}{ }^{+}\right.$monitoring the product ion at $m / z$ 17); trimethylamine $\left(\mathrm{NO}^{+} / m / z 59 ; \mathrm{O}_{2}{ }^{+} m / z 58,59\right)$; hydrogen sulfide $\left(\mathrm{H}_{3} \mathrm{O}^{+} / \mathrm{m} / z\right.$ 35); methyl mercaptan $\left(\mathrm{O}_{2}{ }^{+} / \mathrm{m} / z\right.$ 48); ethyl mercaptan $\left(\mathrm{NO}^{+} / \mathrm{m} / z 62, \mathrm{O}_{2}{ }^{+} / \mathrm{m} / z\right.$ 62); carbon disulfide $\left(\mathrm{O}_{2}+/ \mathrm{m} / z\right.$ 76); ethanol $\left(\mathrm{NO}^{+} / \mathrm{m} / z\right.$ 45,63); formaldehyde $\left(\mathrm{H}_{3} \mathrm{O}^{+} / \mathrm{m} / z\right.$ 31,49); and acetic acid $\left(\mathrm{NO}^{+} / \mathrm{m} / z\right.$ 90). 


\section{Results}

The layout of the Gelita factory site is shown in Figure 2 together with an overview of the surrounding neighborhood.

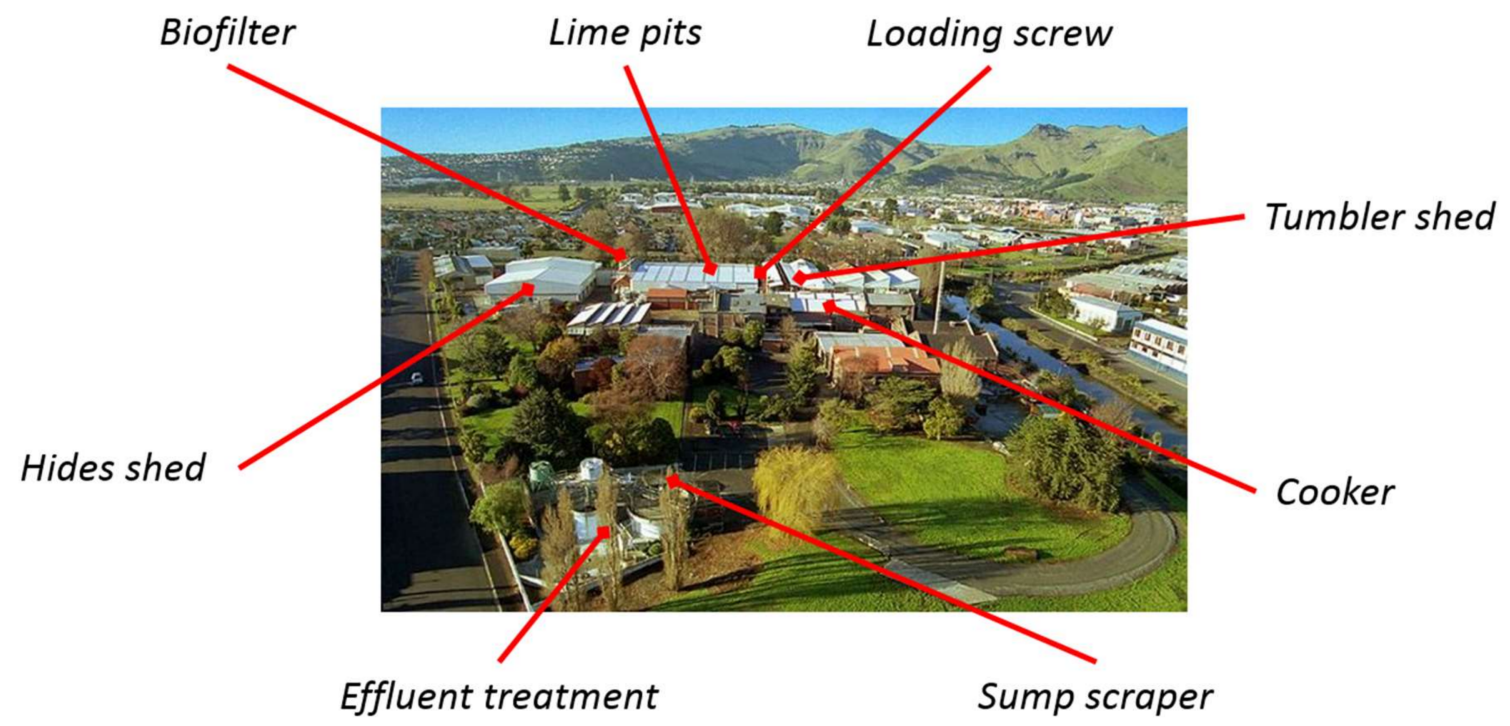

Figure 2. Photograph of the Gelita factory site in Christchurch, annotated with the different processing sites from which samples were taken.

The various operation rooms utilized by the factory are also designated. The Gelita site has been monitored using SIFT-MS technology at different times over several years. The main odors produced in the different operation rooms within the plants are summarized in Figure 3.

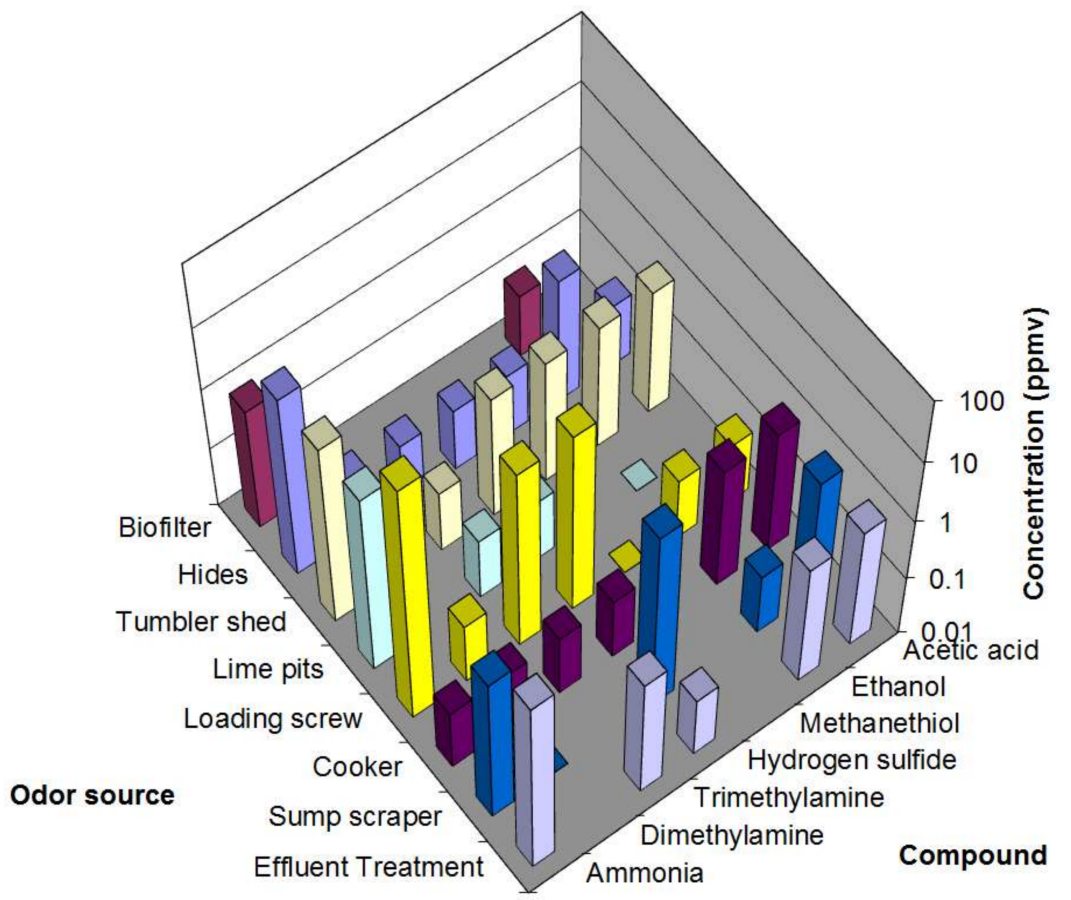

Figure 3. Chemically diverse odor compounds from various sources at the Gelita gelatin factory that have been detected and quantified by SIFT-MS. Note the logarithmic concentration scale. 
Depending on climate conditions, there have been occasions when objectional odors have permeated into the district in the vicinity of the Gelita factory. Although Gelita embarked on engineering changes to reduce odor emissions after 2005, major earthquakes in Christchurch in 2010 and 2011 disrupted this process. In 2016, the decision to evaluate odor elimination technology using a photoionization installation $[24,25]$ (Neutralox ${ }^{\circledR}$ Umwelttechnik GmbH, Hennef, Germany) was made as discussed previously.

The pilot plant deodorizer unit was tested by monitoring samples collected in Tedlar sampling bags at three sites identified as odor sources within the Gelita plant. Grab samples of both inlet air (air sampled at the inlet port of the deodorizer unit) and outlet air (air sampled at the output port of the deodorizer unit) were taken from the hides shed and loading screw (see Figure 2) to assess the effectiveness of the photoionization deodorizer. The filled sample bags were delivered to the Syft Technologies Laboratory for SIFT-MS analysis-all within two hours. The odor losses due to bag absorption or diffusion are minimized by the short time to sampling for both odorized and deodorized air $[34,35]$.

We show in Figures 4 and 5 the results of the effectiveness of the deodorizer at the hides shed and the loading screw. In the hides shed, salted cattle hides are stored in this building before they undergo the process that extracts collagen used in the production of gelatin. Four routine activities are conducted in this shed. These are (i) delivery of salted hides to the shed; (ii) moving hides within the shed; (iii) cutting hides; and (iv) transfer of hides out of the shed to the lime pits. The dashed lines show the human odor threshold in air [36] and provides comparison for the SIFT-MS instrument data. It is evident that the photoionization device reduces the concentrations to below the odor threshold for all odorants shown.

Every day, conditioned cattle hide is transferred from the alkaline lime pits via the loading screws shed to the tumblers for acidulation. The hide is conditioned with lime and caustic and is highly alkaline (pH 12). It is generally of consistent quality. Previous investigations showed that the hide transfer on the loading screw yielded high levels of ammonia and other odors typical of the lime pits from which they originate (see Figure 5), but at higher concentrations due to the agitation of the hides through the loading screw.
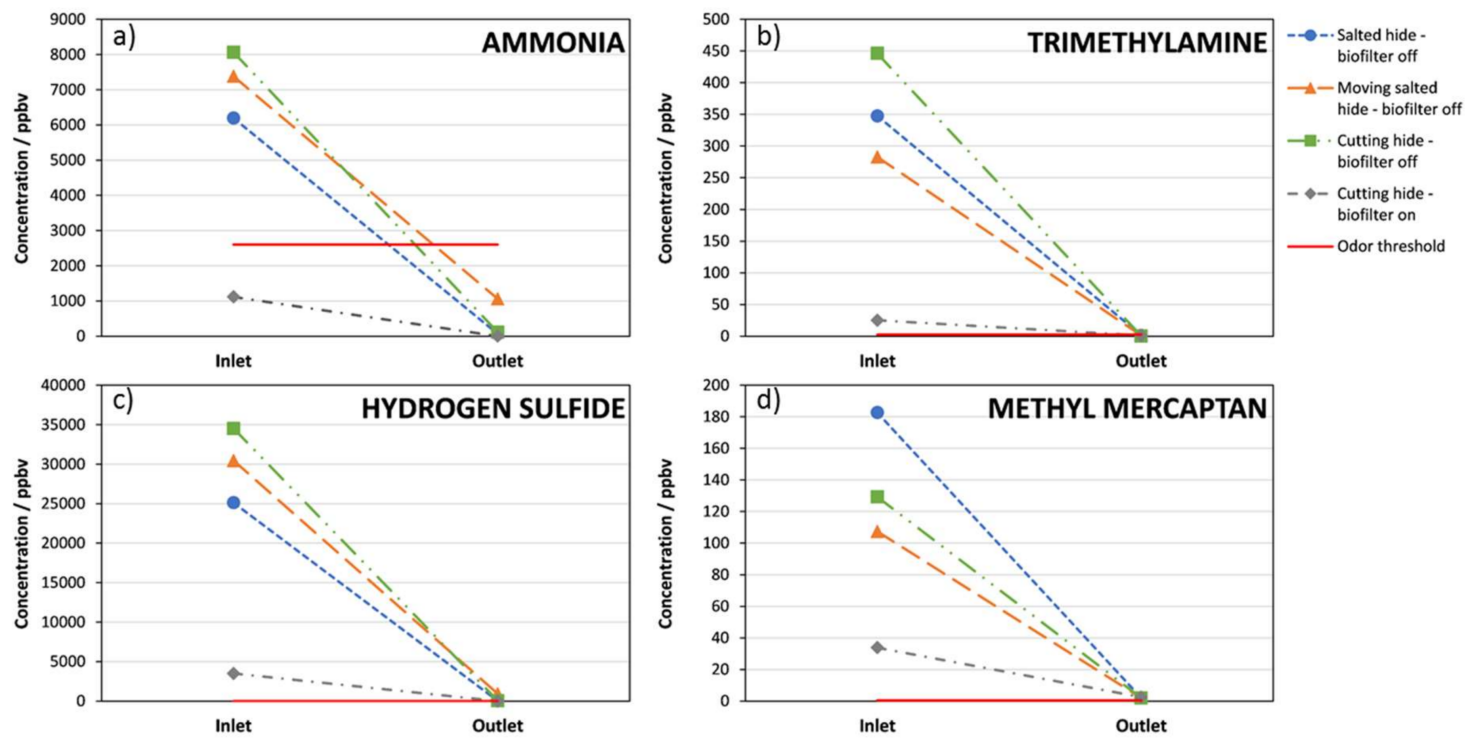

Figure 4. Cont. 

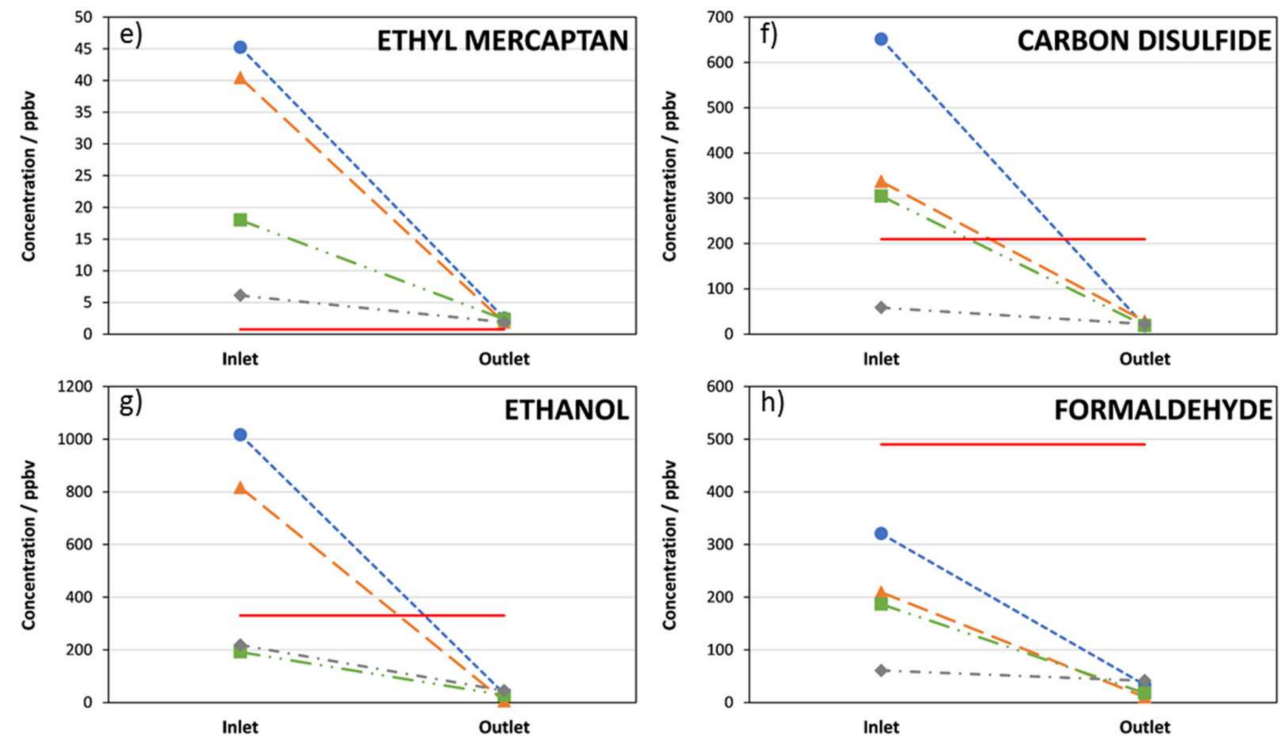

Figure 4. SIFT-MS analysis of (a) ammonia, (b) trimethylamine, (c) hydrogen sulfide, (d) methyl mercaptan, (e) ethyl mercaptan, (f) carbon disulfide, (g) ethanol, and (h) formaldehyde emissions from the hides shed before and after treatment by the photoionization device. The lines shown are to guide the eye between the two SIFT-MS measurements at the inlet and exit ports of the deodorizer. The odor thresholds are from [36].
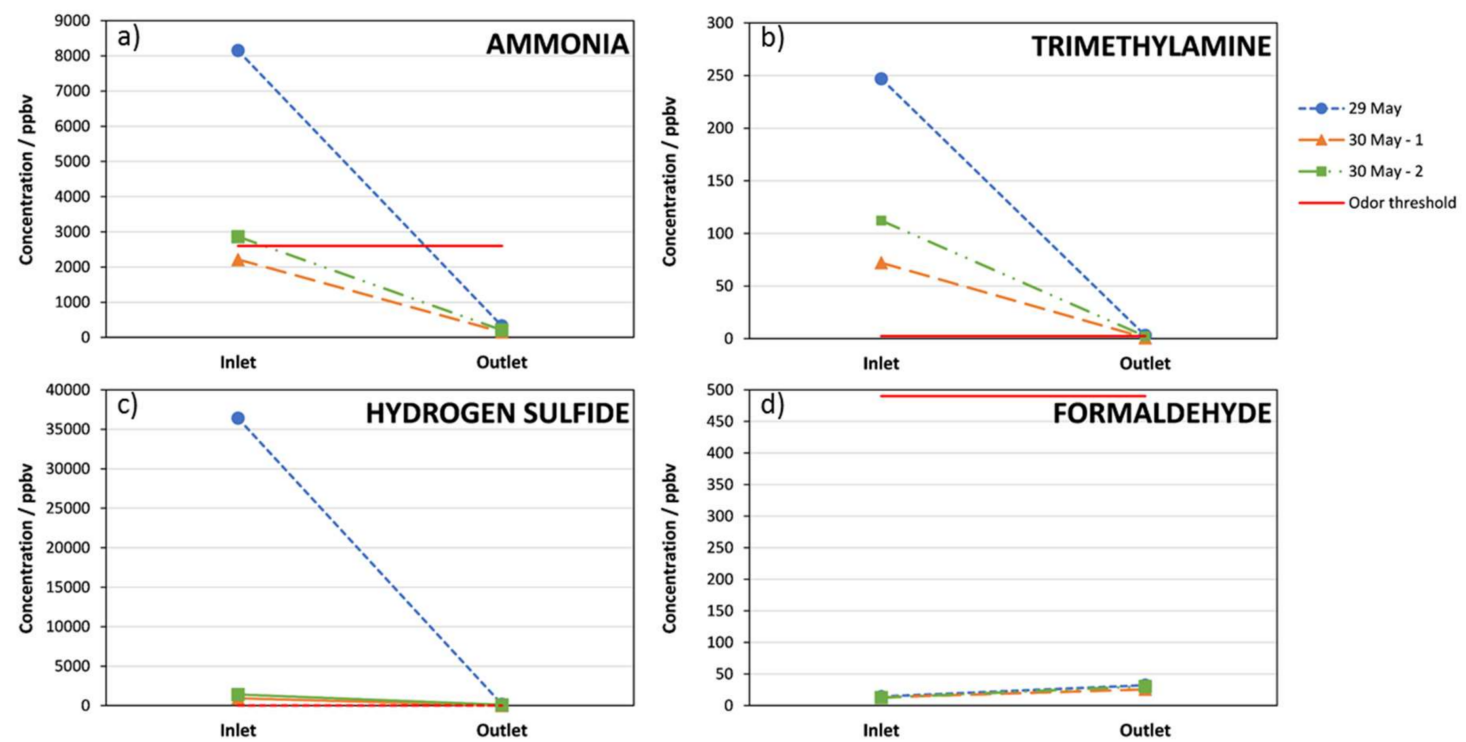

Figure 5. SIFT-MS analysis of (a) ammonia, (b) trimethylamine, (c) hydrogen sulfide, and (d) formaldehyde emissions from the loading screw before and after treatment by the photoionization device. The lines are shown to guide the eye between the two SIFT-MS measurements at the inlet and exit ports of the deodorizer. The odor thresholds are from [36].

The key odorants—ammonia, hydrogen sulfide, and trimethylamine—vary significantly from day-to-day, but the Neutralox ${ }^{\circledR}$ deodorization plant is again effective in removing odors no matter what level enters its inlet.

An exception is formaldehyde, which is both more consistent on a day-to-day basis, and shows an approximately doubling at the outlet, albeit at low concentrations. This may be due to the extent of photolysis applied. However, at these levels it is not a concern for workplace exposure, as the 
US Occupation of Safety and Health Administration lists the permissible 8 hour exposure limit at 750 ppbv [37].

Odor diversity on the loading screw (i.e., after the lime pits) was much less than in the hides shed, suggesting that the alkalization process occurring in the lime pits serve to eliminate some of the specific decay odors.

The evidence that we observed from the Gelita site is that the photoionization device provides effective reductions in the concentration of odorants to below the odorant threshold at the emission source.

\section{Discussion}

These results show how SIFT-MS can be utilized to monitor odors in real time and readily provide quantitative data of the odor composition. It is of course necessary to know the reagent ion-odorant molecule ion kinetics [17], and these are known for most of the common odorants [26-31].

Unlike eNose and other CMOS-based sensors [10,38-40], SIFT-MS readily identifies odorants that may have very different chemical properties as in the Gelita situation and in addition, it quantifies the odorants in real time. There is significant time-benefits over chromatographic based techniques where the odorant identification and quantification step takes place after chromatographic separation of the different odorants. A pre-concentration step may also be required in some analyses that is followed by derivatization prior to injection onto the chromatographic column. For odorants that have very different chemical properties (such as formaldehyde, carbon disulfide, and ammonia), multiple analyses may be required as a result of different column chemistries.

The direct and selective analysis from the reagent ion-odorant molecule ion chemistry that is utilized in SIFT-MS can readily be applied to real time in-situ analysis of odor in the work place. The dynamic range of concentration in SIFT-MS is dependent on the ratio of product ion counts of the odorant product ion to reagent ion counts (see Figure 1 under the analyte quantitation section) [17-19]. This means that a concentration range of five orders of magnitude or more can be accommodated without dilution of the sample as well as enabling the determination of odor thresholds. In the present case at the Gelita factory, up to 8 ppmv of ammonia was recorded at the inlet of the Neutralox ${ }^{\circledR}$ photoionization device down to concentrations for some odors of single-digit ppbv at the outlet.

In the present case presented here, a simple solution was provided to evaluate a deodorant technology based on photoionization. The photoionization technology was found to provide an effective means of reducing factory odors at the source.

\section{Conclusions}

The application of direct mass spectrometry in the form of SIFT-MS has greatly simplified the monitoring of odors. SIFT-MS enables measurements of mixtures of odorant molecules to be monitored effectively. Further, the utilization of different reagent ion-odorant molecule reactions enables analysis of complex mixtures of odorant molecules. In the case study presented, the monitoring of key odors generated in a gelatin factory clearly demonstrated the efficiency of a photoionization device for odor depletion. The device was effective in reducing the levels of the prominent odor molecules responsible for the nuisance value to below the odor threshold.

Acknowledgments: Mary Askey thanks Oliver Augustin and Udo Laser (Neutralox ${ }^{\circledR}$ Umwelttechnik GmbH) for facilitating the short-term trial of the UV photolysis plant.

Author Contributions: Mary Askey provided the samples and the photoionization technology for testing: Helena Barnes and James Olerenshaw carried out most of the SIFT-MS measurements; Vaughan Langford conceived and monitored the experiments; Murray McEwan assisted with the project and wrote the paper.

Conflicts of Interest: The authors declare there were no conflicts of interest. 


\section{References}

1. Araneda, R.C.; Kini, A.D. The molecular receptive range of an odorant receptor. Nat. Neurosci. 2000, 3 , 1248-1255. [CrossRef] [PubMed]

2. Powers, W. The Science of Smell Part 1: Odor Perception and Physiological Response. Iowa State University, 2004. Available online: http:/ /www.aerisa.com/wp-content/uploads/2014/10/3-Science-of-Smell-Parts1-4-Iowa-State-PM1963.pdf (accessed on 20 March 2018).

3. Buettner, A. Springer Handbook of Odor; Springer International Publishing: Cham, Switzerland, 2017.

4. Capelli, L.; Sironi, S.; Del Rosso, R.; Gullot, J.M. Measuring odours in the environment vs. dispersion modelling: A review. Atmos. Environ. 2013, 79, 731-743. [CrossRef]

5. Pickenhagen, W. History of Odor and Odorants. In Springer Handbook of Odor; Buettner, A., Ed.; Springer International Publishing: Cham, Switzerland, 2017; Chapter 1; pp. 1-9.

6. Mackie, R.I.; Stroot, P.G.; Varel, V.H. Biochemical identification of key odor components in livestock waste. J. Anim. Sci. 1998, 76, 1331-1342. [CrossRef] [PubMed]

7. Van Harrevald, P.; Heeres, P.; Harssema, H. A review of 20 years of standardization of odor concentration measurements by dynamic olfactometry in Europe. J. Waste Manag. Assoc. 1999, 49, 705-715. [CrossRef] [PubMed]

8. Mannebeck, D. Olfactometers according to EN 13725. In Springer Handbook of Odor; Buettner, A., Ed.; Springer International Publishing: Cham, Switzerland, 2017; Chapter 24; pp. 545-551.

9. Govardhan, K.; Grace, A.N. Metal/metal oxide doped semiconductor-based metal oxide gas sensors-A review. Sens. Lett. 2016, 14, 741-750. [CrossRef]

10. James, D.; Scott, S.M.; Ali, Z.; O'Hare, W.T. Chemical sensors for electronic nose systems. Microchim. Acta 2005, 149, 1-17. [CrossRef]

11. Escuderos, M.E.; Sanchez, S.; Jiminez, A. Quartz crystal microbalance (QCM) sensor array selection for olive oil sensory evaluation. Food Chem. 2011, 124, 857-862. [CrossRef]

12. Guthrie, B. Machine Olfaction. In Springer Handbook of Odor; Buettner, A., Ed.; Springer International Publishing: Cham, Switzerland, 2017; Chapter 21; pp. 459-482.

13. Beauchamp, J.; Zardin, E. Odorant Detection by On-line Chemical Ionization Mass Spectrometry. In Springer Handbook of Odor; Buettner, A., Ed.; Springer International Publishing: Cham, Switzerland, 2017; Chapter 18, pp. 355-393.

14. Cagliero, C.; Sgorbini, B.; Cordero, C.; Liberto, E.; Rubiolo, P.; Bicchi, C. Enantioselective Gas Chromatography with Cyclodextrin in Odorant analysis. In Springer Handbook of Odor; Buettner, M., Ed.; Springer International Publishing: Cham, Switzerland, 2017; pp. 409-433.

15. Burdack-Freitag, A.; Heinlein, A.; Mayer, F. Material Odor Emissions and Indoor Air Quality. In Springer Handbook of Odor; Buettner, M., Ed.; Springer International Publishing: Cham, Switzerland, 2017; pp. 563-577.

16. Guffanti, P.; Pifferi, V.; Falciola, L.; Ferrante, V. Analysis of odours from concentrated animal feeding operations: A review. Atmos. Environ. 2018, 175, 100-108. [CrossRef]

17. Smith, D.; Spanel, P. Selected Ion Flow Tube Mass Spectrometry (SIFT-MS) for on-line trace gas analysis. Mass Spectrom. Rev. 2005, 24, 661-700. [CrossRef] [PubMed]

18. Spanel, P.; Smith, D. Progress in SIFT-MS: Breath analysis and other applications. Mass Spectrom. Rev. 2011, 30, 236-267. [CrossRef] [PubMed]

19. McEwan, M.J. Direct Analysis Mass Spectrometry in Ion/Molecule Attachment Reaction Mass Spectrometry; Fujii, T., Ed.; Springer Science \& Business Media: New York, NY, USA, 2015; Chapter 8, pp. 263-318.

20. Hera, D.; Langford, V.S.; McEwan, M.J.; McKellar, T.J.; Milligan, D.B. Negative reagent ions for real time detection using SIFT-MS. Environments 2017, 4, 16. [CrossRef]

21. Gomez-Guillen, M.C.; Giminez, B.; Lpez-Cabellero, M.E.; Montero, M.P. Functional and bioactive properties of collagen and gelatin from alternative sources; a review. Food Hydrocolloids 2001, 25, 1813-1827. [CrossRef]

22. Liu, D.; Nikoo, M.; Boran, G.; Zhou, P.; Regenstein, J.M. Collagen and Gelatin. Ann. Rev. Food Sci. Technol. 2015, 6, 527-557. [CrossRef] [PubMed]

23. Yang, H.; Shu, Z. The extraction of collagen protein from pig skin. J. Chem. Pharm. Res. 2015, 6, 683-687.

24. Augustin, O.G.; Little, S. A new odour control option for sewer and pump stations. In Proceedings of the 6th International Conference on Sewer Processes and Networks, Surfers Paradise and Networks, Surfers Paradise, Gold Coast, Australia, 7-10 November 2010. 
25. Althoff, H.; Mizzi, R.; Augustin, O. New odour control technology deals with difficult odours. A case study from one of Europe's largest Waste Water Treatment Plants. In Proceedings of the Australia's National Water Conference and Exhibition, Sydney, Australia, 8-10 May 2012.

26. Spanel, P.; Smith, D. SIFT studies of the reactions of $\mathrm{H}_{3} \mathrm{O}^{+}, \mathrm{NO}^{+}$and $\mathrm{O}_{2}{ }^{+}$with a series of aldehydes and ketones. Int. J. Mass Spectrom. Ion Process. 1997, 165-166, 25-37. [CrossRef]

27. Spanel, P.; Smith, D. Selected ion flow tube studies of the reactions of $\mathrm{H}_{3} \mathrm{O}^{+}, \mathrm{NO}^{+}$and $\mathrm{O}_{2}{ }^{+}$with some organosulfur molecules. Int. J Mass Spectrom. 1998, 176, 167-176. [CrossRef]

28. Williams, T.L.; Adams, N.G.; Babcock, L.M. Selected ion flow tube studies of $\mathrm{H}_{3} \mathrm{O}^{+}\left(\mathrm{H}_{2} \mathrm{O}\right)_{0.1}$ reactions with sulfides and thiols. Int. J. Mass Spectrom. 1998, 172, 149-159. [CrossRef]

29. Spanel, P.; Smith, D. Selected ion flow tube studies $\mathrm{H}_{3} \mathrm{O}^{+}, \mathrm{NO}^{+}$and $\mathrm{O}_{2}{ }^{+}$with several amines and some other nitrogen containing molecules. Int. J. Mass Spectrom. 1998, 176, 203-211. [CrossRef]

30. Midey, A.J.; Arnold, S.T.; Viggiano, A.A. Reactions of $\mathrm{H}_{3} \mathrm{O}^{+}\left(\mathrm{H}_{2} \mathrm{O}\right)_{n}$ with formaldehyde and acetaldehyde. J. Phys. Chem. A 2000, 104, 2706-2709. [CrossRef]

31. Spanel, P.; Smith, D. SIFT studies of the reactions of $\mathrm{H}_{3} \mathrm{O}^{+}, \mathrm{NO}^{+}$and $\mathrm{O}_{2}{ }^{+}$with a series of carboxylic acids and esters. Int. J. Mass Spectrom. Ion Process. 1998, 172, 137-147. [CrossRef]

32. Langford, V.S.; Graves, I.; McEwan, M.J. Rapid monitoring of volatile compounds: A comparison between gas chromatography/mass spectrometry and selected ion flow tube mass spectrometry. Rapid Commun. Mass Spectrom. 2014, 28, 10-18. [CrossRef] [PubMed]

33. Prince, B.J.; Milligan, D.B.; McEwan, M.J. Application of selected ion flow tube mass spectrometry to real time atmospheric monitoring. Rapid Commun. Mass Spectrom. 2010, 24, 1763-1769. [CrossRef] [PubMed]

34. Boeker, P.; Leppert, J.; Lammers, P.S. Comparison of odorant losses at the ppb-level from sampling bags of NalophanTM and TedlarTM and from adsorption tubes. Chem. Eng. Trans. 2014, 40, 157-162.

35. Traube, S.L.; Anhalt, J.C.; Zahn, J.A. Bias of Tedlar bags in the measurement of agricultural odorants. J. Environ. Qual. 2006, 35, 1668-1677. [CrossRef] [PubMed]

36. Van Gemert, L.J. Odour Thresholds: Compilation of Odour Threshold Values in Air, Water and Other Media; Oliemans Punter and Partners: Utrecht, The Netherlands, 2011.

37. US Occupational Safety and Health Administration Lists 8 Hour Exposure Safety Level for Formaldehyde as 750 ppbv. Available online: www.osha.gov (accessed on 20 March 2018).

38. Dung, T.T.; Oh, Y.; Choi, S.-J.; Kim, I.-D.; Oh, M.-K. Applications and advances in bioelectronic noses for odor sensing. Sensors 2018, 18, 103. [CrossRef] [PubMed]

39. Brattoli, M.; de Gennaro, G.; de Pinto, V.; Lovascio, S.; Penza, M. Odour detection methods: Olfactometry and chemical sensors. Sensors 2011, 11, 5290-5322. [CrossRef] [PubMed]

40. Gebicki, J. Application of electrochemical sensors and sensor matrixes for measurement of odorous chemical compounds. Trends Anal. Chem. 2016, 77, 1-13. [CrossRef] 